\section{Stern tube seals under static condition: A multi-scale contact modeling approach}

\author{
F Xavier Borras $\mathbb{D}$, Mohammad Bazrafshan, Matthijn B De Rooij \\ and Dik J Schipper
}

Proc IMechE Part J:

J Engineering Tribology

202I, Vol. 235(I) 18I-195

(C) IMechE 2020

Article reuse guidelines:

sagepub.com/journals-permissions DOI: I0.1 | 177/|350650|20925583 journals.sagepub.com/home/pij

(SSAGE

\begin{abstract}
A thermomechanical model of a stern tube seal has been developed by paying particular attention to the contact between the seal and the shaft. The finite element method is used to capture the macroscopic behavior of the seal while roughness was evaluated at a microscopic level by applying the boundary element method. The seal material was independently characterized, and the results were used to calibrate the material constitutive model used for the seal. Two specialized setups were built to validate the model in terms of radial force, contact width, and percolation threshold. By combining the two models, the strains, stresses, temperature, and the limits of static tightness can be predicted at high accuracy for a wide range of operating conditions.
\end{abstract}

\title{
Keywords
}

Lip seal, sealing, stern tube, modeling

Date received: 6 September 2019; accepted: 18 April 2020

\section{Introduction}

The effective sealing of the stern tube has always been a challenge for marine engineers. The lubricant filling the stern tube needs to stay in the stern tube. The most common method is to fit a series of rubber rings between the rotating shaft and the stern tube as shown in Figure 1. These components prevent the ingress of seawater into the stern tube, while, at the same time, limiting the spillage of the lubricant from the stern tube into either the sea or the engine chamber. Two sets of stern tube seals are positioned at each end of the stern tube: the aft package (oil-seawater interface) and the forward package (oil-air interface). Separate lubricant tanks feed the compartments left between the various seals, allowing control of the hydrostatic oil pressure acting on each sealing step. ${ }^{1}$ The pressure difference between seals is specific to the seal-specific position and the ship design.

Stern tube seals are usually made of highly inert elastomers that are capable of withstanding elevated temperatures, lubricants, and seawater. Specially tailored FKM compounds are the common choice for such seals, with the fluorine content defining their inertness and mechanical properties. ${ }^{2}$ Additional compounds are used in the final formulation to ease its processing, stiffness, chemical compatibility, and to improve the tribological characteristics. Stern tube seals often include a fabric reinforcement to stiffen the elastomeric component.
Stern tube seals are one of the largest types of lip seals. These components are widely used in static, rotary, and reciprocating sealing applications. Rotary lip seals are designed, so that a sharp tip at the edge of the lip acts as a physical barrier to prevent leakage through the seals. Stern tube seals are mounted on the metallic shaft sleeve bolted to the shaft and are often referred as shaft liners (see Figure 1).

Rotary lip seals have been used for almost a century, and extensive research has been carried out on the underlying technology. Surprisingly, their working mechanism is not yet fully understood. ${ }^{3}$ Various working principles have been identified by Jagger, ${ }^{4}$ Horve, ${ }^{5}$ van Bavel, ${ }^{6}$ Salant, ${ }^{7}$ Stakenborg, ${ }^{8}$ and Wennehorst ${ }^{3}$ among others. However, there is not a generally accepted theory that can accurately predict the performance of rotary lip seals. The authors consider it probable that several mechanisms develop simultaneously, and, depending on the application and running conditions, one or another mechanism

Faculty of Surface Technology and Tribology, University of Twente, Enschede, The Netherlands

\section{Corresponding author:}

F Xavier Borras, Faculty of Engineering Technology, University of Twente, Drienerlolaan 5 Horstring N I 34 Enschede, Overijssel 7522 NB, The Netherlands.

Email: f.borrassubirana@utwente.nl 


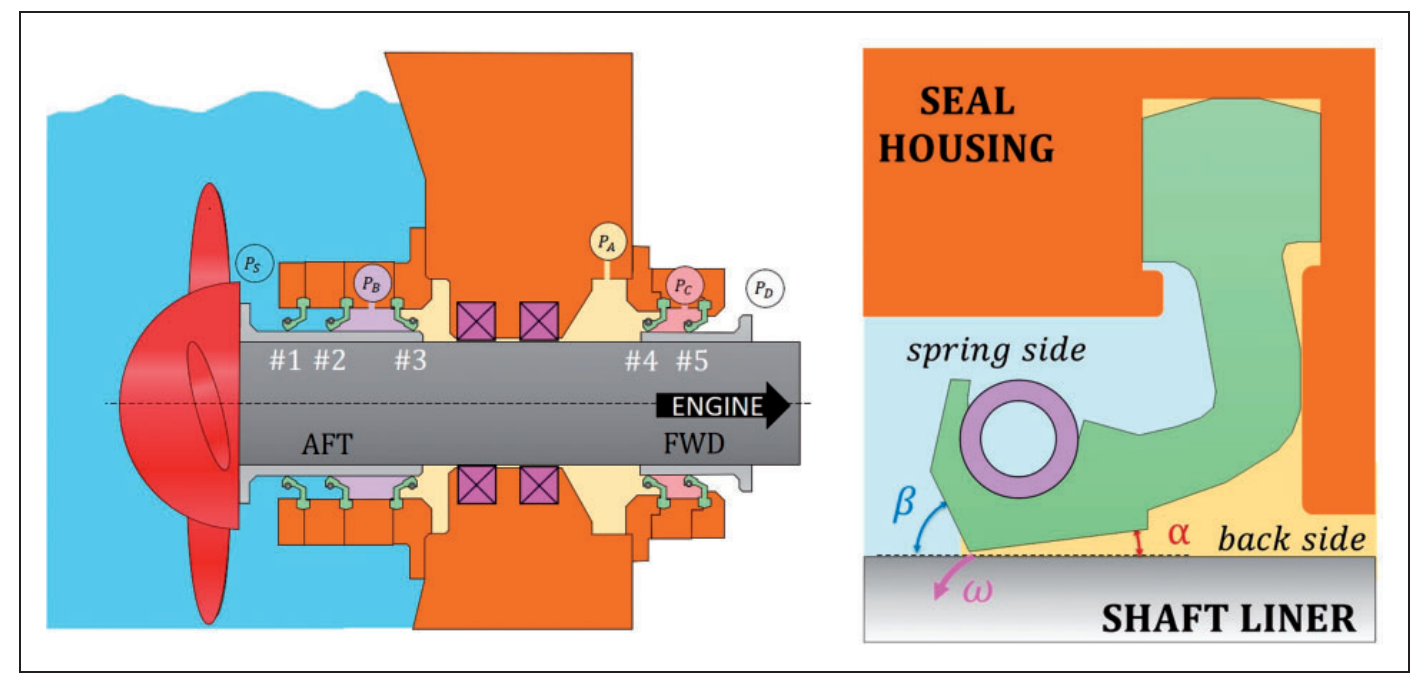

Figure I. Sketch of a stern tube of a ship (left) and seal detail (right).

becomes dominant. Notice that the static and the dynamic sealing mechanisms are completely different. ${ }^{4}$ Their large size and the severe running conditions under which they operate make stern tube seals a particularly challenging type of rotary seal in terms of manufacturing, consistency, and laboratory testing.

This paper focuses on a key variable that largely determines the lubrication regime of lip seals and the prevention of leakage when the shaft is at rest: the contact force between seal and shaft liner. Lip seals generally work under compression in the radial and axial directions while elongated in the circumferential direction. The resultant radial load determines the minimum load-carrying capacity that the thin film of lubricant running between the liner and the seal needs to operate within the wear-less full-film lubrication regime. Consequently, the sealing load determines the frictional torque, the leakage, the wear rate, the power consumption, and the lifespan of a stern tube seal. ${ }^{1,9}$ The static contact pressure profile, and hence the total contact force, depends on the following five aspects: seal geometry, seal material properties, Garter spring, pressure difference, and temperature. Each is discussed below.

The seal-shaft contact force is a radially uniformly distributed load along a circumference of several hundreds of centimeters, and hence it is not straightforward to measure. A specific method is repeatedly reported in the literature: the split-shaft setup. ${ }^{8,10,11}$ Such test rig consists of a two semi-cylindrical jaws arrangement. One of the jaws is fixed to the bench table while the other semi-circular jaw seats on leaf springs, and it is able to slide along a rail. When the two jaws are set apart a specific distance, they form an almost-complete cylinder representing the shaft. When the seal is mounted on the jaws, a certain load results that pushes the jaws together (see Figure 4). This unidirectional load is measured and is related to the distributed radial load between the seal and the shaft. The split-shaft setup can be placed in a temperature-controlled chamber, so that both the impact of the thermal expansion of the components and the softening or hardening of the elastomer are measured. $^{12}$ Lee et al. ${ }^{13}$ presented an alternative method to measure the contact force, based on the use of an inflatable mandrel. That approach has the advantage of allowing the diameter of the shaft to be varied. A non-destructive approach was presented by Tasora et al., ${ }^{14}$ in which the seal could be directly characterized by measuring its response to the misalignment of the shaft.

The contact area between the seal and the shaft is often measured by mounting the seal on a hollow shaft made of a transparent material. ${ }^{8,12}$ Under ambient conditions, the contact pressure profile spans only along a few tenths of millimeters, thus complicating the measurement of local pressures. Lee et al. ${ }^{13}$ used a pressure-sensitive foil to determine the pressure profile at the contact. One indirect way to reveal the contact distribution involves measuring the displacement of the seal tip in the circumferential direction after a slight rotation of the shaft. Although inaccurate due to the unknown friction coefficient, a nonuniform displacement that is in agreement with the expected parabolic pressure profile has often been reported. 6,8

Finite element (FE) models are used to predict the contact pressure profile of seals. It is often assumed ${ }^{11}$ that the pressure profile does not vary along the circumferential direction, so the seals are modeled assuming axisymmetry. A non-uniform pressure, non-uniform temperature distribution, and shaft-seal misalignment are therefore disregarded. The elastomer is often modeled by linear elastic ${ }^{15}$ or hyperelastic constitutive models such as the Neo-Hookean ${ }^{3}$ or the Mooney-Rivlin. ${ }^{8,14,16}$ The Garter spring is usually modeled as a distributed radial load, ${ }^{17}$ as an independent body with a fitted stiffness, ${ }^{14}$ or using a concentrated spring load. ${ }^{8,13}$ Wenk et al. ${ }^{18}$ presented a 
multi-scale FE model that included the surface roughness that until then had been disregarded.

Although much research has been conducted on lip seals, most of the research focuses on smaller nonpressurized seals, and its applicability to stern tube seals has not yet been demonstrated. This investigation contributes to the scarce literature on large-sized elastomeric seals operating under pressurized conditions. Additionally, seal models usually restrict the displacement of the outer boundaries of the seal. ${ }^{13,17,19}$ While this is beneficial to the convergence of the model, it is inaccurate for seals which are clamped to housing parts, e.g. stern tube seals and O-rings. The lack of published research on this application led to a step-by-step approach of reviewing the common assumptions applied when modeling sealing components. Such an approach outlines the specific contribution of each of the components of the system which presents a significant advantage when tuning the seal design. Three different validation methods are presented to corroborate the fidelity of the stern tube seal model developed. Dedicated test rigs were developed, and so the seals were validated under actual pressurized conditions which is, to the best of the authors' knowledge, not been reported in

Table I. Summary of the tests and computational models developed.

\begin{tabular}{lll}
\hline Characterization & Computational models & Validation \\
\hline Elastomer & Yeoh hyperelastic material & Contact area \\
Garter spring & Axisymmetric FE model & $\begin{array}{r}\text { Percolation } \\
\text { threshold }\end{array}$ \\
Surface roughness & Contact BE model & Radial force \\
\hline
\end{tabular}

the literature. The novel coupling between the macroscale and microscale allowed satisfactory prediction of the sealing limit of the components, i.e. the pressure difference at which a seal starts to leak. This research aims to determine the contact pressure and area of stern tube seals, thereby creating a solid base on which to build more advanced models.

\section{Materials and methods}

The model presented requires the characterization of the elastomeric compound, the Garter spring, and the surface topography of the contact. Further experiments were later carried out to validate the model against the joint performance of the various parts of the stern tube seal. Table 1 summarizes the tests conducted and the computational models developed.

An axisymmetric FE model was developed to capture the macroscopic behavior of the seal. Next, the FE model was coupled to a boundary element (BE) surface contact model to link the macroscale and microscale. That model is able to reliably predict the radial force, static strains, stresses, and sealing limits over a wide range of pressures. Figure 2 shows the general structure of the model developed. The results were validated under an operating pressure range that is typical for a stern tube seal, i.e. up to 1.5 bar pressure difference.

\section{Material characterization}

Although the properties of the shaft liner and housing parts were obtained from datasheets, those of both the seal and the Garter spring were mechanically characterized. The results will be used as input parameters to the multiscale contact model.

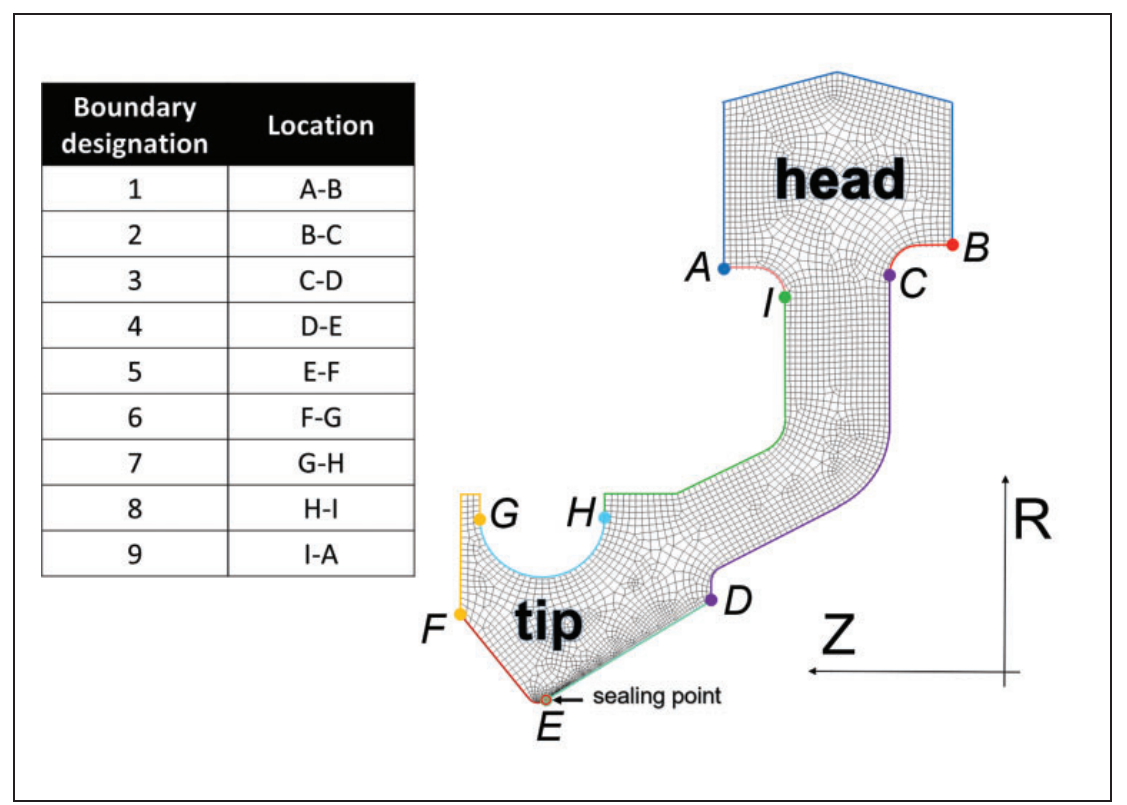

Figure 2. Schematic of the thermomechanical multi-scale static stern tube seal computational model. 
Stern tube seals are commonly made of fluoroelastomer compounds often of the Viton ${ }^{\circledR}$ brand. The high fluorine content allows for elevated running temperatures while providing exceptional inertness against the mineral oils used in the stern tube seals. ${ }^{20}$ Fluoroelastomers are a mixture of several monomers tailored for a particular application, and they are generally cured by bisphenol. However, for the highest fluorine contents (as those studied in this research), cure-site-monomers are added to the formulation so peroxides are used for its vulcanization. ${ }^{2}$ The diverse compositions of such elastomeric compounds require independent characterization of each formulation.

It is common to test the seal material using samples cut directly from the final component. In this way, there should be no difference between the curing states of the definitive parts and of the testing slabs. Unfortunately, this method showed a significant spread of results which were attributed to dimensional inaccuracies and the presence of micro-cracks generated when extracting the samples from the finished parts. Therefore, independently, cured material slabs were used. Elastomers are viscoelastic materials characterized by mechanical properties that vary over time when strained or loaded, leading to stress relaxation and creep. Furthermore, elastomers present a different response when tested under tension, compression, or shear strains. Due to the Mullins effect, the initial stretches are unique events, and, after a few loading cycles, the material response stabilizes to a repeatable stress-strain curve. ${ }^{21}$ As a result, the maximum strain ever reached by the specimen determines the response of the elastomer. In addition to a certain strain-rate dependency, the material behavior when loading is usually different to the response when unloading, i.e. elastomers usually exhibit hysteresis. Temperature also influences the fluoroelastomer, leading to possible hardening or softening of the materia $\left.\right|^{22}$ and, together with the excitation frequency, ${ }^{21}$ determining the viscoelastic characteristics of the material.

The fluoroelastomer compound used for molding the seals was characterized under a set of loading modes, strain rates, and temperatures to calibrate the constitutive material model. Tensile tests (Zwick Roell, Ulm, Germany), namely uniaxial extension, were carried out to examine the most relevant elastomer properties for the application: components orientation, strain-rate dependence, or relaxation. Stern tube seals operate for long periods of time; therefore, the stress-strain combinations of interest are the ones obtained after most of the stress relaxation is undergone. Evidence of varying stress relaxation behaviors under tension and compression has previously been reported for fluoroelastomers. ${ }^{23}$ The viscoelasticity of the elastomer was studied following the procedure described by Dalrymple et al. ${ }^{24}$

The sea temperature governs the stern tube lubricant temperature and consequently the seal temperature. However, due to friction heating, significantly higher temperatures develop on the tip of the seal. ${ }^{1}$ The temperature-dependent viscoelasticity and the high thermal expansion of elastomers also need to be accounted for. The effects of bolt temperature (and viscoelasticity) on the mechanical properties between -80 and $120^{\circ} \mathrm{C}$ were obtained by performing dynamic mechanical analysis (DMA) using a DMA Gabo Eplexor 2000N (Netzsch, Selb, Germany).

\section{Two-scale model of the seal-shaft contact}

The COMSOL Multiphysics ${ }^{\circledR}$ commercial FE package was used to develop the thermo-mechanical model of the stern tube seal. The model is axisymmetric, so perfect alignment, concentricity, and roundness of the seal, shaft, and housing components are assumed. The initial geometry of the seal was provided by a seal supplier and is shown in Figure 3. After molding the seals, the remaining burr on the tip edge is manually removed. The curvature after this step was measured using a confocal microscope, and it is included in the initial geometry of the model.

Both housing parts, the liner and the seal, are each modeled as independent bodies. The seal head of stern tube seals is tightly clamped between the housing parts leading to a stressed situation. As a result, the seal head is not fixed, but a certain displacement is allowed as listed in Table 2. The grooves clamping the seal head were removed after observing that they did not significantly impact the contact force between seal and liner once the thickness of the seal head was decreased.

The Garter spring is implemented on the model as an inward radial boundary load acting on the seal circular groove. The magnitude can be deduced from the spring elongation and the spring

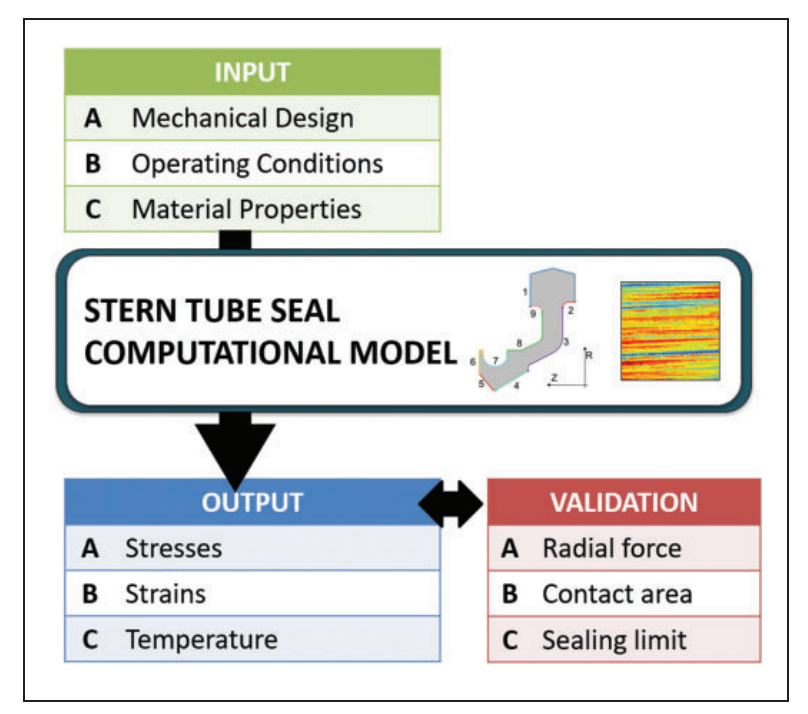

Figure 3. Mesh of the selected stern tube seal model with boundaries. 
Table 2. Boundary conditions for solving the virtual work equation (see Figure 3).

\begin{tabular}{lll}
\hline Position & Boundary number & Boundary condition \\
\hline Seal head and back-up wall & $1,2,3,9$ & Contact model (penalty term) \\
Seal tip & 4,5 & Contact model (augmented Lagrangian) Coulomb friction \\
Spring groove & 7 & Spring radial load \\
Spring-side of the seal & $5,6,7,8,9$ & Pressure load \\
Back-side of the seal & $2,3,4$ & Pressure load \\
\hline
\end{tabular}

characteristics (equation (8)) or from the radial force measurements obtained from the split-shaft setup.

The pressure on each side of the seal is modeled as a true follower load by varying the nodal forces according to the deformed configuration. The sealing point is assumed to be located at the tip of the seal which is where the highest local contact pressure develops. Consequently, the pressures on each side of the seal are applied to the whole seal surface up to the tip of the seal.

The Coulomb friction model was defined between the seal and the liner with a constant coefficient of friction $\mu_{s}$. Under normal operating conditions, namely fully lubricated and rotating, the resultant tangential load in the axial direction is expected to be minor. Note that the circumferential friction force (out-of-plane) is neglected in axisymmetric models.

The Yeoh hyper-elastic model (equations (1) to (3)) was selected for its ability to capture the fluoroelastomer stress-strain response together with its simplicity, ${ }^{25}$ i.e. the strain energy density only depends on the distortional part of the first invariant $I_{1}^{*}$ of the right Cauchy-Green tensor. A mixed formulation was used to prevent volumetric locking of the mesh. The mixed formulation, also referred as $\mathrm{u}-\mathrm{P}$ formulation, consists in introducing the mean pressure as an extra degree of freedom, in this way, avoiding numerical problems and overly stiff models. The relaxed stress-strain curves together with the split-shaft measurements were used to calibrate the model

$$
\begin{aligned}
& \psi\left(I_{1}^{*}\right)=\sum_{i=1}^{3} C_{i 0}\left(I_{1}^{*}-3\right)^{i}+\frac{\kappa}{2}(\mathrm{~J}-1)^{2} \\
& I_{1}^{*}=\mathbf{J}^{\frac{3}{2}}\left(\lambda_{1}^{2}+\lambda_{2}^{2}+\lambda_{3}^{2}\right) \\
& \sigma=\frac{2}{\mathbf{J}}\left[C_{10}+2 C_{20}\left(I_{1}^{*}-3\right)+3 C_{30}\left(I_{1}^{*}-3\right)^{2}\right] \operatorname{dev}\left[\mathbf{b}^{*}\right] \\
& \quad+\kappa(\mathbf{J}-1) \mathbf{I}
\end{aligned}
$$

The heat equation was also solved together with the virtual work equation. Regardless of whether the material characteristics are considered temperaturedependent or not, the thermal expansion of the

\begin{tabular}{|c|c|c|}
\hline Position & $\begin{array}{l}\text { Boundary } \\
\text { number }\end{array}$ & Boundary condition \\
\hline $\begin{array}{l}\text { Seal head and } \\
\text { back-up wall }\end{array}$ & $1,2,3,9$ & Temperature \\
\hline Seal tip & 4,5 & $\begin{array}{l}\text { Thermal contact: } \\
\text { continuity }\end{array}$ \\
\hline Spring-side of the seal & $5,6,7,8,9$ & Convection \\
\hline Back-side of the seal & $2,3,4$ & Convection \\
\hline
\end{tabular}
parts still occurs, necessitating a double-direction
Table 3. Boundary conditions for solving the energy balance equation.

coupling between the virtual work and heat balance equations.

The heat convection between the seal and the fluid was modeled using a preset oil bath temperature and a constant convective heat transfer coefficient. ${ }^{8,17}$ When the system is static, no frictional heating develops; therefore, the temperature of the parts and fluids together with material properties determines the temperature gradient along the stern tube seal (Table 3). The continuity boundary condition was used to model the heat transferred between seal and liner.

The model described is clearly geometrically nonlinear. Although the magnitude of the strains is not significant, Green-Lagrange strains were used to account for the rotation of the seal body. COMSOL Multiphysics ${ }^{\circledR}$ solves the virtual work and energy equations (fully coupled) using the total Lagrangian approach.

Once the macroscopic FE model is validated against the radial force and contact width measurements, it is possible to reliably estimate the specific loading of the real contact area. For this reason, the loading of the seal surface topography was modeled using a BE-based contact model assuming a semi-infinite half-space and homogeneous mechanical properties. ${ }^{26}$ For that, the surface patch is assumed to repeat itself along the circumferential direction of the contact, i.e. cell periodicity. The contact model uses the conjugate gradient method to estimate the local deformation and the pressure distribution resulting from the loading situation. The seal material stress was shown to be fairly linear to strains up to 0.5 (see Figure 6). For that, and for simplicity, the seal asperities were assumed to be linearly elastic using the properties listed in Table 4 . The soft seal material 
conforms to the shaft surface increasing the real contact area, and adhesion is nevertheless assumed negligible due to surface contamination effects. Thereby, the Boussinesq solution for elastic deformation was used (see equation (4)). A smooth glass surface was considered, and so the initial gap was exclusively defined by the surface topography of the seal

$u_{e}(x, y)=\frac{1-v^{2}}{\pi E} \int_{-\infty}^{+\infty} \int_{-\infty}^{+\infty} \frac{p\left(x^{\prime}, y^{\prime}\right)}{\sqrt{\left(x-x^{\prime}\right)^{2}+\left(y-y^{\prime}\right)^{2}}} \mathrm{~d} x^{\prime} \mathrm{d} y^{\prime}$

The model allowed variation of the total contact force, allowing the minimum load required for sealing the contact to be found. A conservative approach was adopted by assuming zero flow only when contact was detected, i.e. regardless of the characteristics of sealed fluids. A pair of surfaces was considered to be gas tight when no leakage path (in the axial direction) spanned from side-to-side of the contact when loaded (see Figure 19). The minimum pressure

Table 4. Material properties used for the stern tube seal hardware (for linear elastic seal material).

\begin{tabular}{llll}
\hline & Stern tube seal & Shaft liner & Seal housing \\
\hline$E(\mathrm{MPa})$ & 14.0 & $200 \mathrm{e} 3$ & $106.5 \mathrm{e} 3$ \\
$v(-)$ & 0.49 & 0.27 & 0.35 \\
$\rho\left(\mathrm{kg} / \mathrm{m}^{3}\right)$ & 1900 & 7700 & 8800 \\
$\left.C_{p}(\mathrm{~J} / \mathrm{kg} \cdot \mathrm{K})\right)$ & 1670 & 1909.7 & 376 \\
$k(\mathrm{~W} /(\mathrm{m} \cdot \mathrm{K})$ & 0.25 & 25 & 60 \\
$\alpha_{T}(\mathrm{I} / \mathrm{K})$ & $275 \mathrm{e}-6$ & $10 \mathrm{e}-6$ & $18.5 \mathrm{e}-6$ \\
\hline
\end{tabular}

providing a tight contact, i.e. the quotient of the force and the contact area, is referred as the sealing limit of the contact.

\section{Validation}

A large-dimension split-shaft test rig was designed and built to measure the radial force between the stern tube seal and the shaft liner (see Figure 4). However, the versatility of such a test rig is limited: each seal size requires its matching jaws to act as the shaft liner. Therefore, for this research, the stern tube seal model previously presented that had a nominal diameter of $200 \mathrm{~mm}$ was used.

The load required to keep the correct separation between the jaws when a seal is mounted on them is dependent on the inward radial force between the seal and the liner $F_{r_{t o t}}$ via equation (5). Note that the moving jaw is not pulled further than its position conforming a circumference, i.e. the $200 \mathrm{~mm}$, as shown in Figure 4. Once the circumference is conformed, the separation between the fixed and the moving jaws may allow that part of the seal material flow into it. However, the jaws and the control system are designed, so that the separation between the jaws is minimum, i.e. few tenths of a millimeter. The tangential load between seal and jaws shown in Figure 4 is included, assuming Coulomb friction $\mu_{s}$, so that

$$
F_{r_{t o t}}=\frac{F_{m} \pi}{\left(1+\mu_{s}\right)}
$$

A capacity-distance sensor (Micro-Epsilon, Ortenburg, Germany) is used to measure the separation between the jaws. A control loop is implemented in LabView, so that a stepper motor (Haydon Kerk

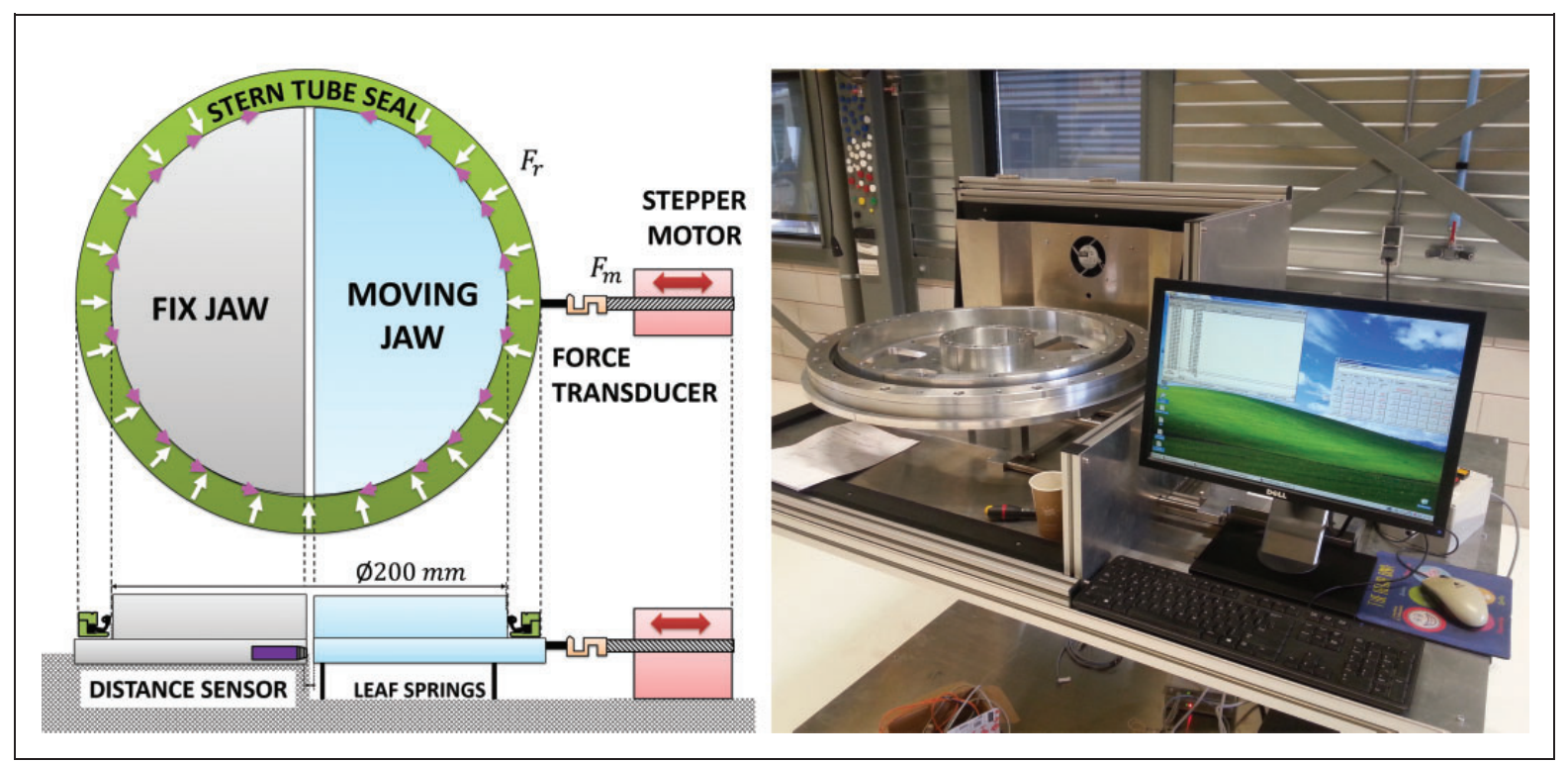

Figure 4. Split-shaft test setup to measure the radial force between stern tube seals and shaft liner. 
Motion Solutions, Waterbury, USA) keeps the jaws a set distance apart. The S2M load cell (HBM, Darmstadt, Germany) mounted between the stepper motor and the moving jaw measures the pulling force exerted by the motor $F_{m}$. The stress relaxation of the elastomer and the spring force is measured over time. The setup was validated by measuring standard O-rings the material properties of which were independently measured using a tensile tester. Analogously to the procedure used for Garter springs (equation (7)), the circumferential and radial forces of an O-ring can be related to the stress measured when pulling it on a tensile tester. The tensile stress results were found to be in good agreement with the measurements conducted when mounting the O-ring on the split-shaft setup. Lubrication of the seal-shaft liner contact did not significantly impact the results.

Four different configurations were tested on the split-shaft setup (see Table 5). Such an approach allowed the progressive validation of the computational model and to spot the source of inaccuracies. As expected, the characteristic stress relaxation of viscoelastic material makes the radial load between seal and shaft decrease over time. It was observed that most of the force decay occurs after $300 \mathrm{~s}$; therefore, this is set to be the measurement time of each test.

Table 5. The four configurations tested in the split-shaft test rig.

\begin{tabular}{llll}
\hline Configuration & Stern tube seal & Garter spring & Housing \\
\hline A & Yes & No & No \\
B & Yes & Yes & No \\
C & Yes & No & Yes \\
D & Yes & Yes & Yes \\
\hline
\end{tabular}

A major contribution to the radial load between the stern tube seal lip and the shaft liner arises from the pressure difference between the sealing fluids. The split-shaft arrangement cannot measure the radial load under pressurized conditions, so an additional setup was developed allowing measurement of the width of the contact between seal and liner under actual operating pressures (Figure 5). The test rig is configured to include a hollow glass shaft on which the seal is mounted. Through the glass, the contact area between the transparent shaft and the seal can be directly observed. Using the frustrated total internal reflection technique, ${ }^{27,28}$ the contact area is considered to be the location at which the evanescent wave is reflected by the seal. Both sides of the seal were independently pressurized, and the seal-tip displacement was captured by a precision camera (DinoLite, Taiwan, China).

The contact width and its position were measured along the circumference, and the results were used to validate the estimations produced by the seal FE computational model. The impact of uniformly pressurizing the seal was also studied. As stress varies over time, so does the displacement of the seal, implying that the contact area is time-dependent.

The same setup allowed the determination of the minimum pressure needed to keep the seal airtight (defined as the air percolation threshold). The flow rate (leakage) through the seal contact was measured using a ball flow meter (EM-Technik, Maxdorf, Germany). The threshold was found by increasing the pressure at the back-side of the seal until a flow rate was observed. Additional measurements were taken at various leakage rates, so that a trend could be observed.

\section{Results}

In this section, the experimental results obtained are presented along with the matching model predictions.

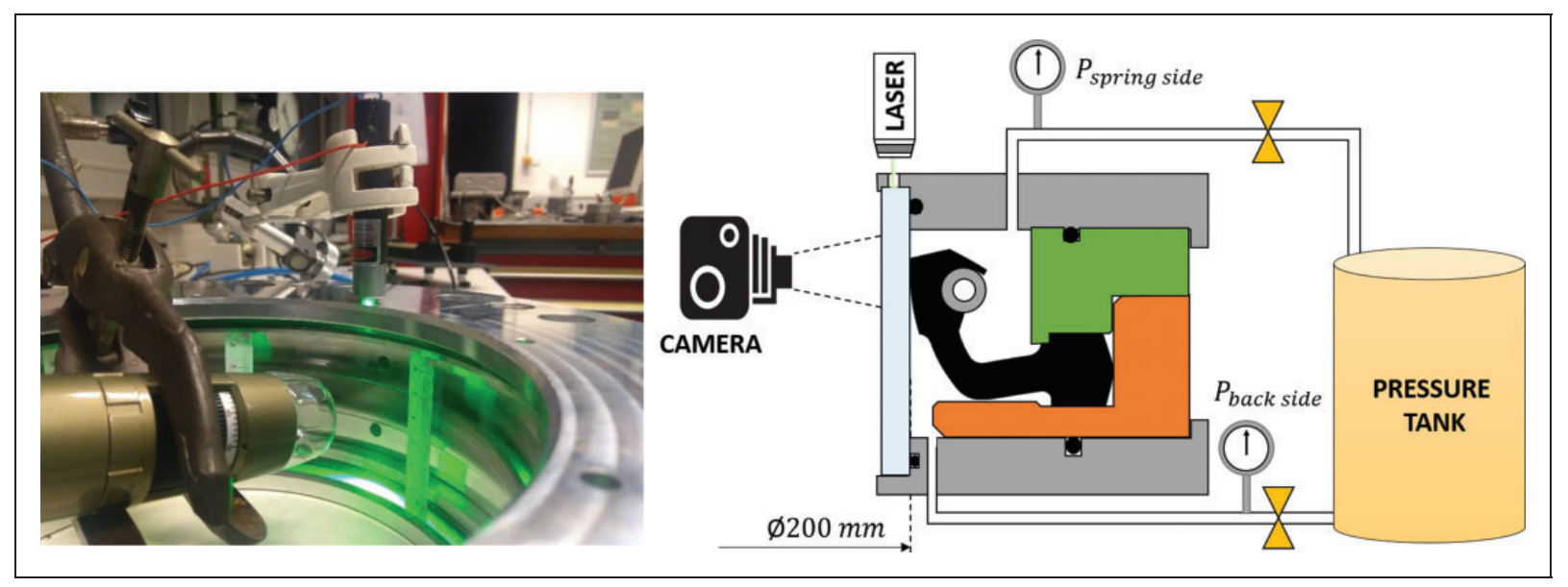

Figure 5. Test bench with a hollow glass shaft to measure the contact area and leakage rate under actual operating pressure conditions. 


\section{Seal material}

Dumbbell B-type specimens were acclimatized for $10 \mathrm{~min}$ beforehand at the set temperature before testing them on the tensile tester. The strain was measured using contacting extensometers; the tensile tester load was zeroed before clamping the sample and an initial pre-tension of $0.1 \mathrm{MPa}$ was imposed. The specimens were cycled as described by Dalrymple et al. ${ }^{24}$ to obtain the stress-strain curves together with the stress-relaxation characteristics for each strain (see Figure 6). The initial length and section of the specimens were updated after each strain cycle, and each test was repeated at least three times.

The strain rate at which the material is set for relaxation was swept from 2 to $250 \mathrm{~mm} / \mathrm{min}$ showing a certain strain-rate dependency that was only significant at the highest strain rates. Therefore, the material was considered strain-independent. Although the strain rate is irrelevant under static seal conditions, it will influence the seal when varying the shaft speed or when operating under misaligned shaft-seal conditions. The material showed a weak anisotropy when compared to dumbbell specimens that had been stamped in perpendicular directions. Additional compression tests were carried out up to $-30 \%$ strain showing a higher stiffness under compression than under tension. The relative stress decay is plotted in Figure 7, evidencing the non-linear viscoelasticity of the material. Hence, the stern tube seals which operate under a higher pressure difference (resulting in higher strains) will experience a greater stress decay than the seals operating under lower strains. The amount of relative relaxation decay is dependent on the strain rate at which the strain is set. However, after $300 \mathrm{~s}$, the final stress becomes independent of the loading strain rate.

The effect of temperature on the elastomer was studied by applying DMA. The result of a temperature sweep from -80 to $120^{\circ} \mathrm{C}$ at a frequency of $2 \mathrm{~Hz}$

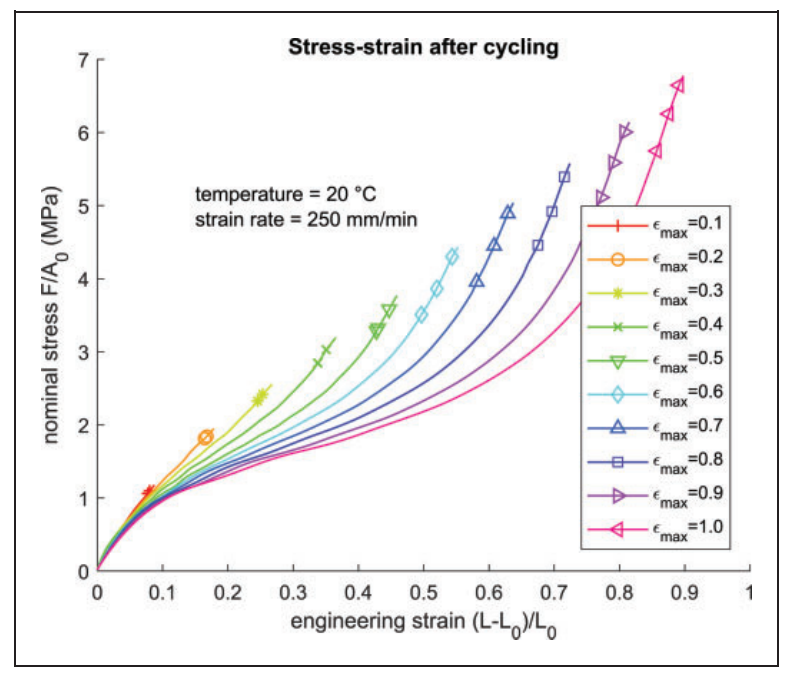

Figure 6. Stress-strain curves after Mullins and recovery at $20^{\circ} \mathrm{C}$ (loading strain rate of $250 \mathrm{~mm} / \mathrm{min}$ ). and $1 \%$ strain is shown in Figure 8. The DMA confirmed that the elastomer undergoes a certain amount of temperature softening until reaching $40^{\circ} \mathrm{C}$ at which a temperature-independent rubber plateau is reached.

The Yeoh hyper-elastic constitutive material model is fitted to the relaxed stress-strain curves ${ }^{24}$ yielding the Yeoh parameters $\mathrm{C}_{10}, \mathrm{C}_{20}$, and $\mathrm{C}_{30}$ listed in Table 6 . The seal material was left temperature-independent as the model validation was conducted at room temperature. The fitting of the tension and compression

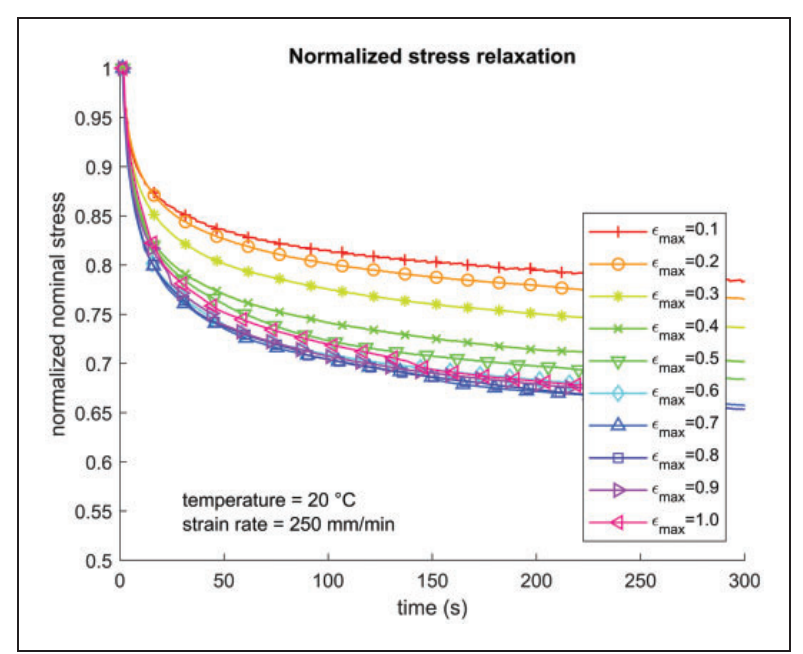

Figure 7. Normalized stress relaxation at various strains at $20^{\circ} \mathrm{C}$ (loading strain rate of $250 \mathrm{~mm} / \mathrm{min}$ ).

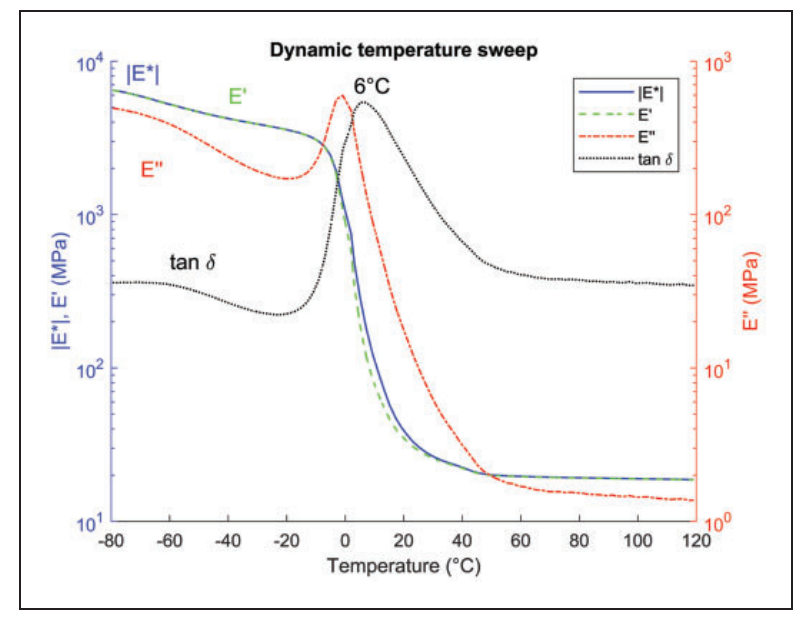

Figure 8. DMA temperature sweep.

Table 6. Parameters used for the Yeoh hyperelastic model.

\begin{tabular}{lll}
\hline Hyperelastic Yeoh parameters $(\mathrm{MPa})$ & \\
\hline Yeoh parameter & $C_{10}$ & 2.50 \\
Yeoh parameter & $C_{20}$ & $-0.6 \mathrm{I}$ \\
Yeoh parameter & $C_{30}$ & 0.54 \\
Bulk modulus & $\kappa$ & le4 \\
\hline
\end{tabular}


curves at $20^{\circ} \mathrm{C}$ was performed using Abaqus/CAE ${ }^{\circledR}$ software and compared with the results obtained using the split-shaft measurements. Results will be discussed later and shown in Figure 11.

\section{Garter spring}

The Garter spring characteristics were measured using a tensile tester ${ }^{5}$ to measure the pre-tension $\left(P_{I}=\right.$ $11.61 \mathrm{~N})$ and the spring stiffness $(S=0.32 \mathrm{~N} / \mathrm{mm})$. When the spring is assembled and mounted on a shaft of diameter $D_{s}$ (see Figure 9), the linear response deduced from the measurements can be decomposed into the circumferential and radial directions ${ }^{29}$ as shown in equations (6) to (8)

$$
\begin{aligned}
& P_{c}=P_{I}+S\left(\pi D_{s}-\pi D_{r i}\right) \\
& P_{r}=\frac{2 P_{c}}{D_{s}} \\
& P_{r}=2\left[\frac{P_{I}}{D_{s}}+\pi S\left(1-\frac{D_{r i}}{D_{s}}\right)\right]
\end{aligned}
$$

This formulation assumes the spring's linear behavior in the circumferential direction; this applies if the lateral bending stiffness is neglected, and the coils are considered to be fully separated. It is also assumed that the radial load contribution to the shaft-seal contact is uniformly distributed along the perimeter of the contact.

\section{Surface roughness}

The surface topography of a new seal was measured using a confocal microscope (Sensofar, Barcelona, Spain). A replicating compound was used to obtain the seal surface topography suitable for microscopy (Microset, Leicestershire, UK) and that topography is shown in Figure 10.

The surface roughness presents a clear wave pattern oriented in the axial direction. Such an undulated profile comes from the turning marks of the metal mold. The statistical roughness parameters are listed in Table 7.

\section{Radial force}

Four seals were measured on the split-shaft setup at least five times per configuration (see Table 5), leading to the radial force values shown in Figure 11. The results are compared to the FE model predictions both with and without the spring and housing parts constraints.

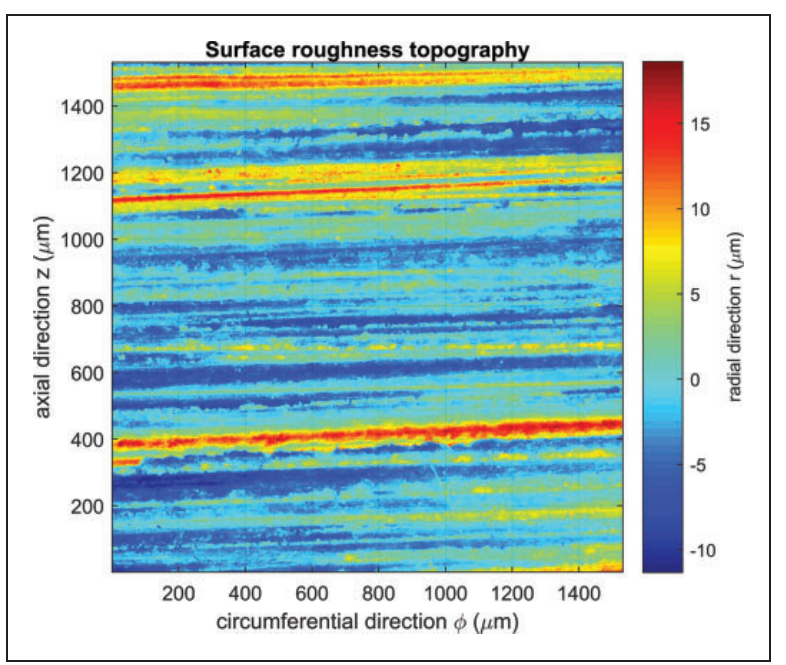

Figure 10. Surface roughness topography of the tip of a new stern tube seal. Note the turning marks of the mold spanning on the circumferential direction.

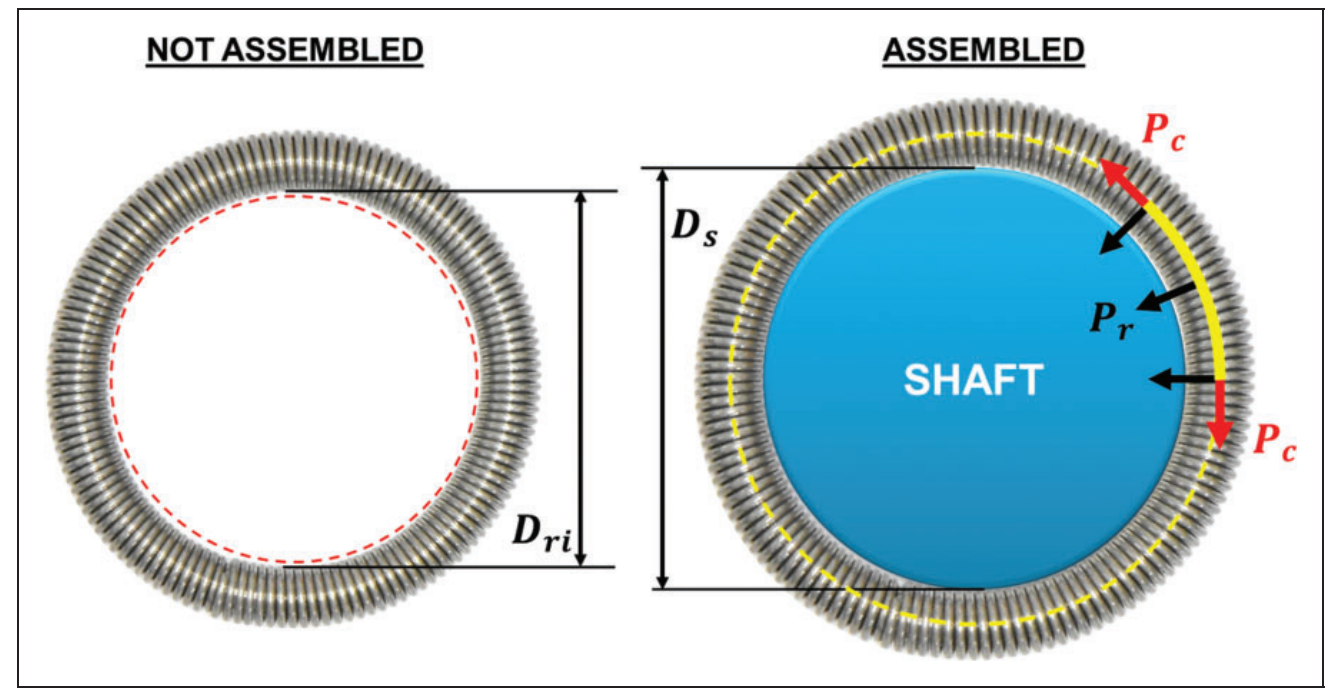

Figure 9. Garter spring force decomposition. 
Table 7. Statistical surface roughness parameters.

\begin{tabular}{ll}
\hline & New seal \\
\hline$S_{a}$ & $3.52 \mu \mathrm{m}$ \\
$S_{q}$ & $4.61 \mu \mathrm{m}$ \\
$S_{p}$ & $30.46 \mu \mathrm{m}$ \\
$S_{v}$ & $13.14 \mu \mathrm{m}$ \\
$S_{\mathbf{z}_{5}}$ & $43.44 \mu \mathrm{m}$ \\
$\boldsymbol{S}_{\mathbf{k}}$ & 0.87 \\
$\boldsymbol{K}_{\mathbf{s}}$ & 4.39 \\
\hline
\end{tabular}

The dimensional accuracy of the jaws and seals, the elastomeric compound composition, differences in the curing state, post-curing shrinkage, the amount of strain each seal had undergone, the testing temperature, the assembling of the seal within the housing parts, and the housing-shaft alignment will all lead to a certain spread in the measurements. As reported by Gabelli et al., ${ }^{19}$ the model predictions underestimate the radial load of the seal by $5 \%$. Parameter $C_{10}$ was slightly increased, so the aforementioned inaccuracies - together with the limitations of hyperelastic models-were compensated for. Note that although the only difference between configurations $\mathrm{A}-\mathrm{B}$ and $\mathrm{C}-\mathrm{D}$ is the presence of the Garter spring, the contributions differ. This shows that the spring load is partially supported by the housing parts in configuration D. The load difference between configurations $\mathrm{A}$ and $\mathrm{B}$ is in agreement with that estimated by equation (8). It is interesting to observe that the radial force in configuration $\mathrm{A}$ (no spring and no housing parts) arises from the circumferential stretch of the material, and this amount is doubled when the seal-housing components are present in configuration $\mathrm{C}$.

\section{Contact width}

Using the glass cylinder setup, captions of the seal tip were taken at pressure differences from 0 to $1.5 \mathrm{bar}$ (see Figure 12). To show the almost-incompressible nature of the elastomer compound, the top and bottom chambers of the setup in Figure 5 were connected by a pipe equalizing the pressure on both sides of the seal. Next, using the precision camera, the overall pressure was increased up to 2 bar showing no difference between the surface captions at the minimum and maximum pressures.

The wavy pattern observed on the seal topography becomes evident on the back-side of the seal, where the contact only occurs on the roughness peaks (Figure 10). Measurements and model predictions are plotted together in Figure 13. The contact width was measured at four different points of the contact after $300 \mathrm{~s}$. The FE model underestimates the contact width, because a smooth contact between the seal and

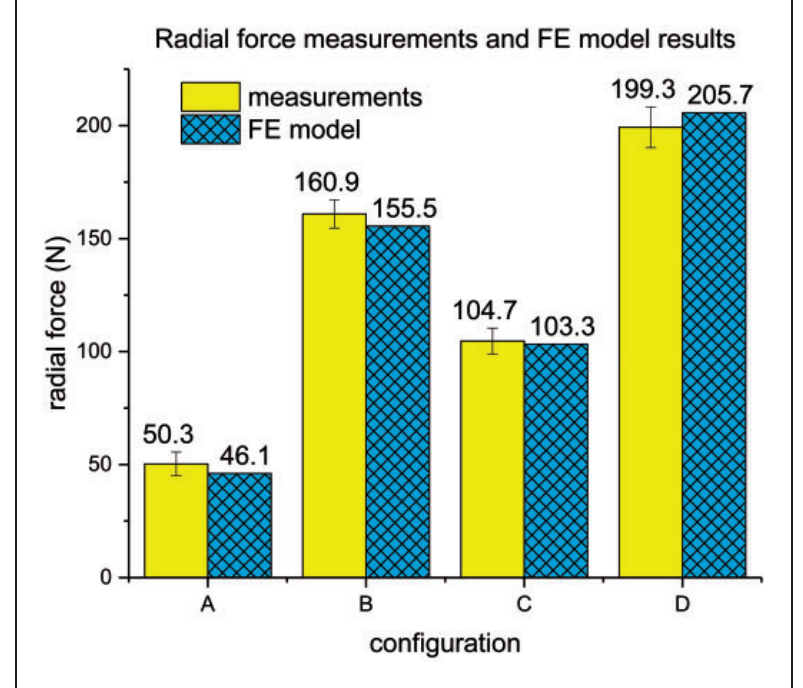

Figure II. Radial force under the four configurations tested (see Table 5) and the loads predicted by the FE model.

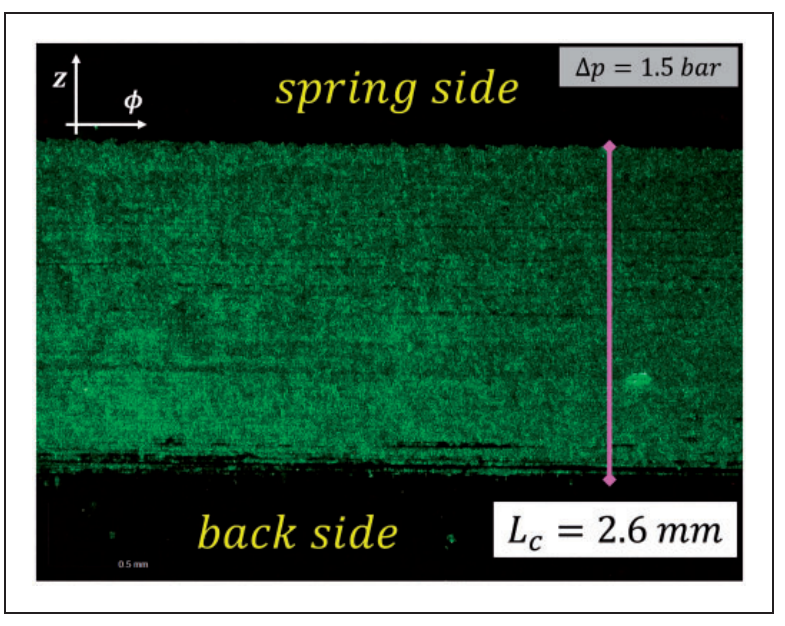

Figure 12. Caption of the contact area on the glass shaft setup ( $\Delta P=1.5$ bar $)$. The turning marks of the mold are shown along the contact and become evident at the back-side of the seal.

the shaft is assumed. ${ }^{19}$ The measurements and the model predictions showed good agreement when the surface roughness was accounted for by adding $S_{z_{5}} / 2$ to the seal profile as shown in Figure 17. The friction between the seal and the glass prevents the sliding of the seal tip as pressure increases. The increase of the standard deviation in response to pressure difference shown in Figure 13 is attributed to the larger loads imposed on the seal.

\section{Leakage and sealing pressure}

Using the same glass setup, the seal was inversely pressurized, i.e. with a greater pressure on the backside than on the spring-side. The pressure at the backside of the seal was steadily increased until the flow rate (leakage) along the seal could be measured. 
Sometime was left between intermediate measurements, so that the seal material had time to adjust to the new strain conditions. That procedure was

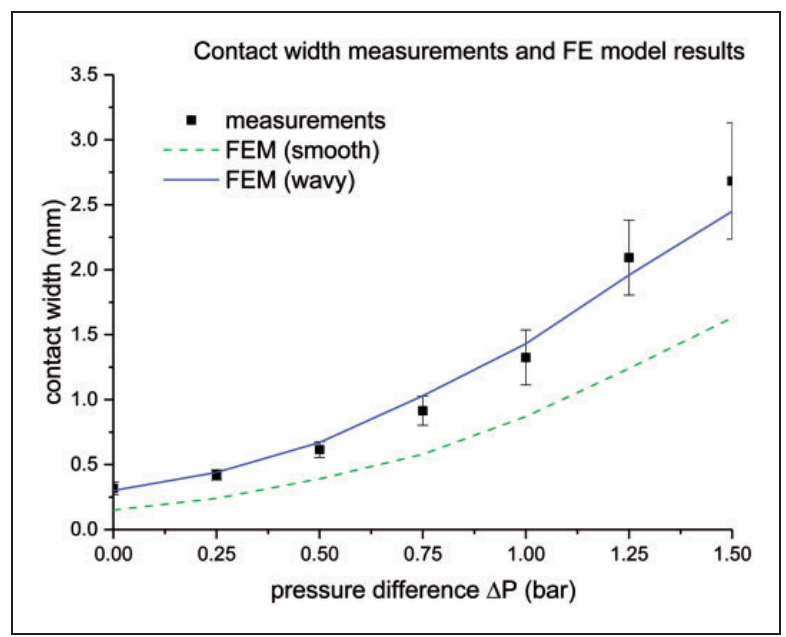

Figure 13. Contact width measurement under various pressure differences using the hollow glass shaft setup. The prediction of the FE model (smooth) and the impact of adding $\mathrm{S}_{\mathrm{z}_{5}} / 2$ (wavy). repeated in both loading and unloading situations, and the results are plotted in Figure 14. The lowest pressure difference leading to leakage is referred as the opening pressure of the seal. Since the resolution of the flow meter is $0.01 \mathrm{~L} / \mathrm{min}$, extra measurements were taken, so the opening pressure can be extrapolated as shown in Figure 14

\section{FE model}

The final position of the seal is shown to be highly dependent on pressure difference $\Delta P$, i.e. the sealing pressure. As the pressure difference increases, the tip of the seal moves closer to the seal head. The contact area steadily increases in response to increasing pressure as the back-side angle decreases. The role of the back-up ring becomes clear when the pressure difference $\Delta P$ reaches 1.0 bar (see Figure 15).

Once the seal contacts the back-up ring, the contact area rapidly increases leading to the characteristic bell mouth-shaped pressure distribution (see Figures 16 and 17). The distribution of the contact load on a wider contact area leads to a decrease in the maximum contact pressure. The maximum contact pressure for

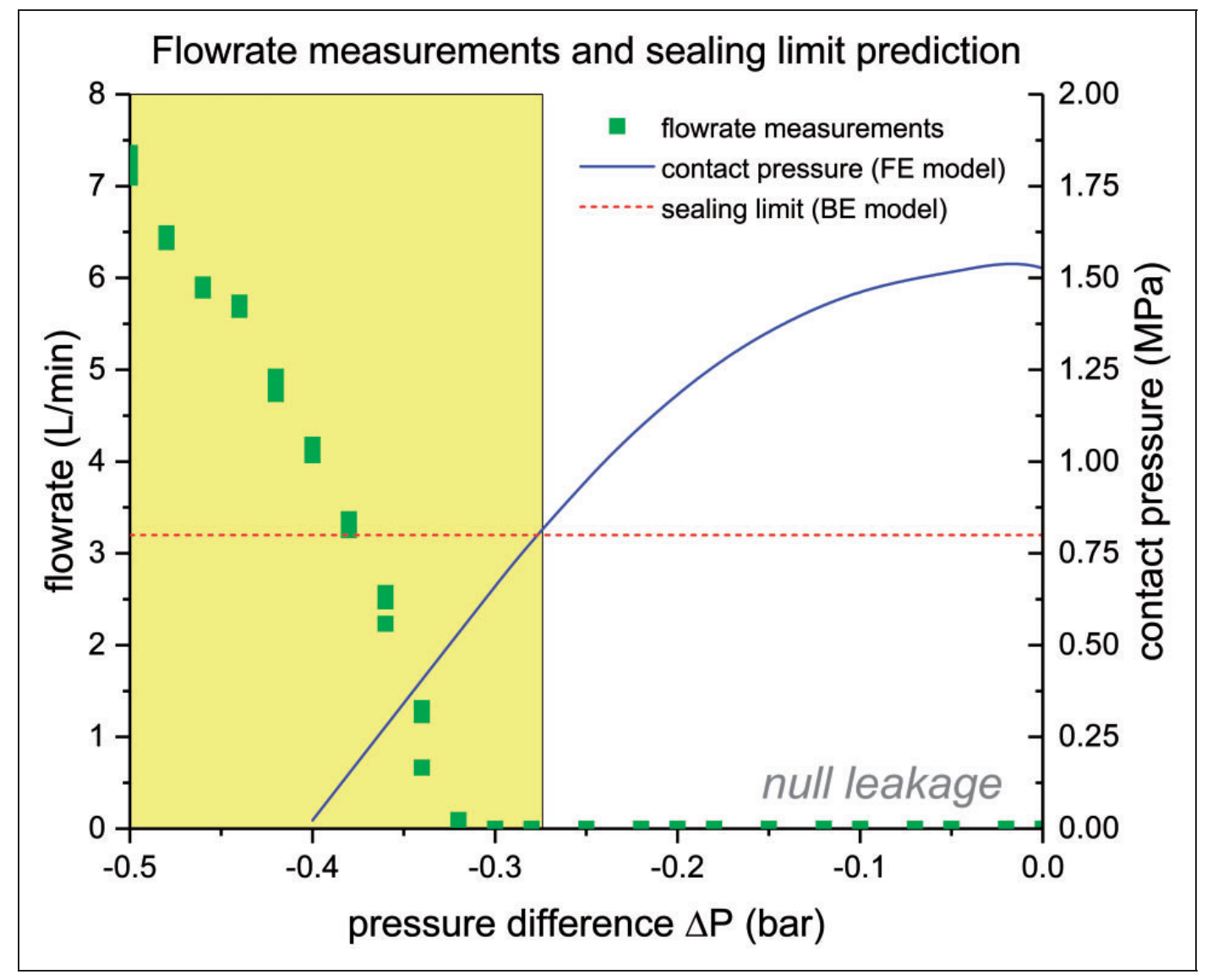

Figure 14. Flow rates measured on the glass shaft setup under various pressure differences (dots). The maximum contact pressure is predicted by the FE model when the seal is inversely pressurized (solid line). The dashed line shows the minimum contact pressure required for a tight surface, i.e. sealing limit, predicted by the BE model (see Figure 19). The shaded part corresponds to the pressure differences where leakage is expected. 


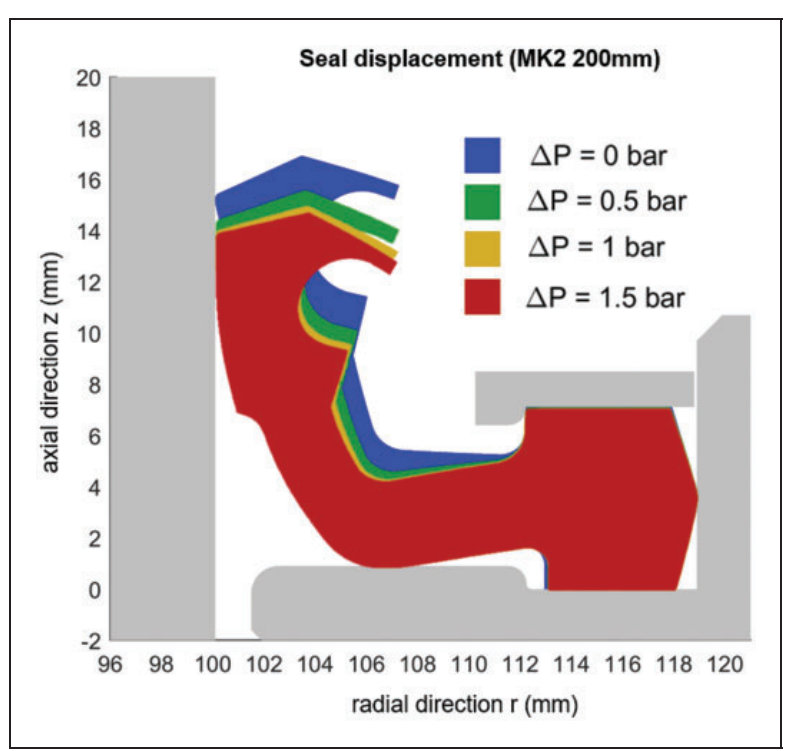

Figure 15. Seal-displacement estimation obtained with the stern tube seal FE model.

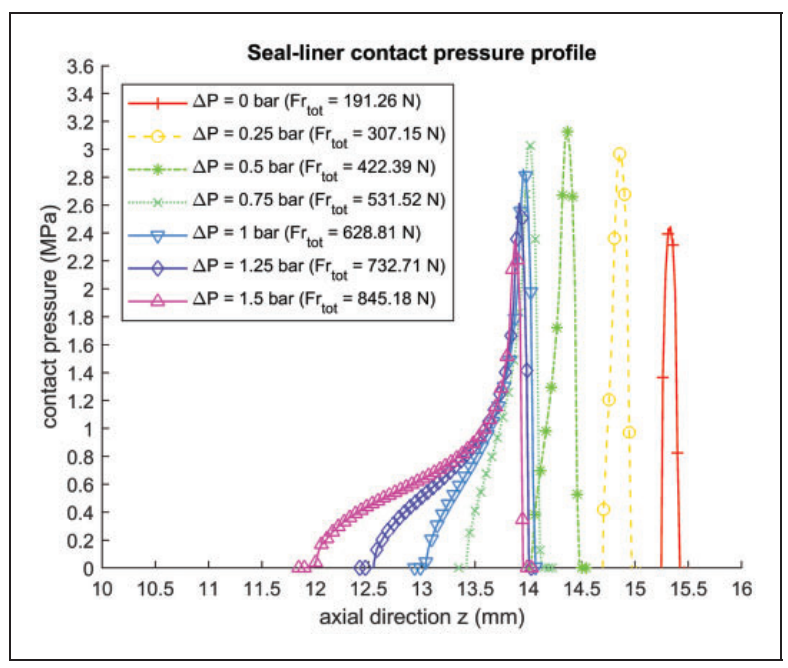

Figure 16. Contact pressure profiles under a range of pressure differences $\left(\mu_{s}=0.0\right)$.

all the cases is located at the edge of the spring-side, thereby validating the sealing point assumption shown in Figure 3.

Figure 18 shows the contribution of the elastomer, the spring, and the pressure difference to the seal-shaft contact force under various levels of pressurization. The elastomer force is a result of the inherent beam force of the seal lip and the hoop force. Note that the contribution of the pressure difference is only higher than the combined contribution of the spring and the material once the pressure difference $\Delta P$ exceeds 0.5 bar. As shown in Figure 1, each seal in the stern tube operates under a particular pressure difference, which results in a seal-specific shaft-liner contact force and, consequently, in a specific tribological pair for each of the stern tube seals.

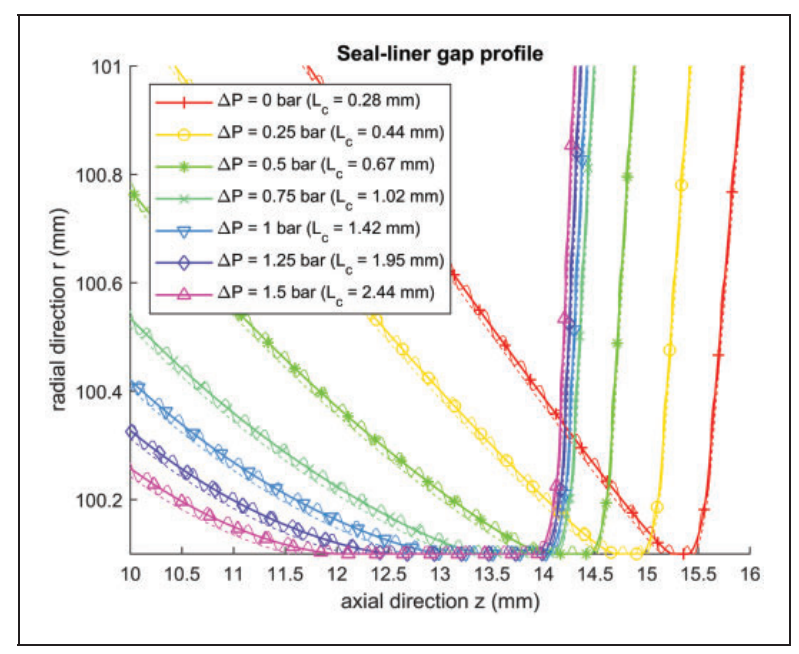

Figure 17. Gap profile under a range of pressure differences $\left(\mu_{s}=0.0\right)$. A wavy profile with an amplitude of $S_{z_{5}} / 2$ is overlapped on the seal-tip profile showing the magnitude of the elastomer roughness.

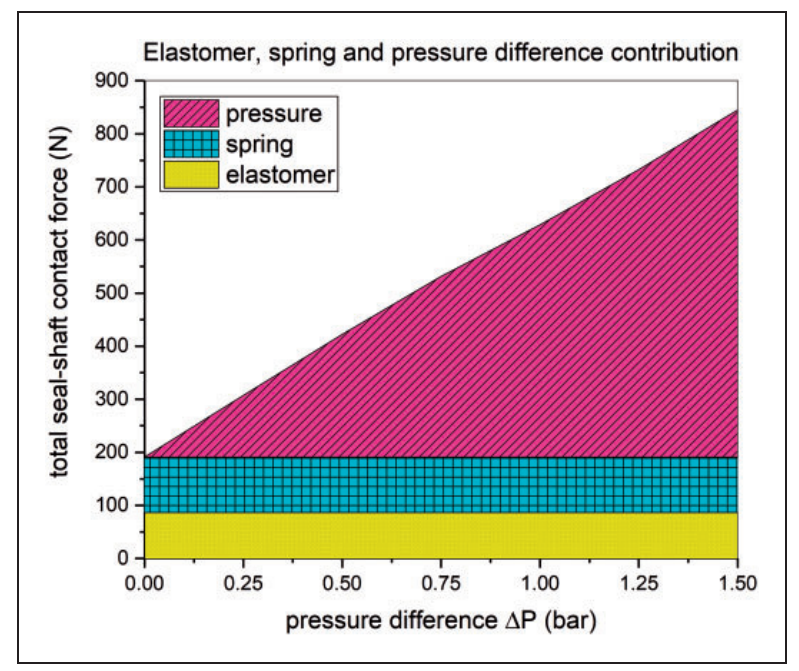

Figure 18. Contribution to the total seal-shaft contact force by the elastomer, the Garter spring, and pressure difference at various pressure levels.

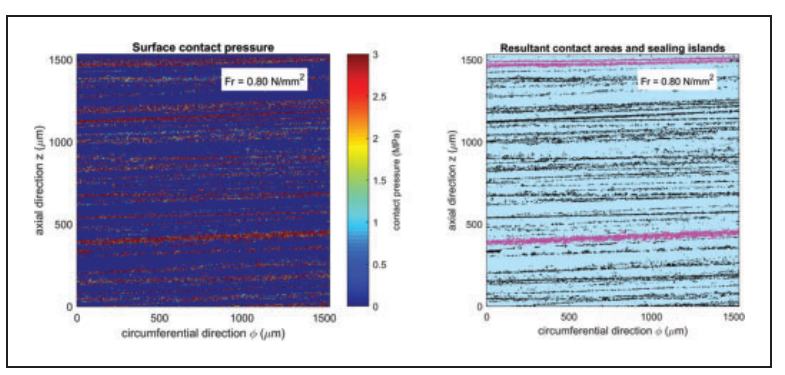

Figure 19. Pressure distribution (left) and resultant contact areas depicted in black and pink (right). The areas in pink are the first sealing islands spanning from side-to-side in the circumferential direction, i.e. where a gas tight situation is considered. 


\section{Surface contact BE model}

The contact between the seal and the shaft was modeled using a BE surface contact model under various loads. In this way, the contact force threshold at which leakage occurs could be spotted and compared with the flow rates measured on the glass shaft test rig. The seal topography measurements (Figure 10) and the material properties listed in Table 4 were used to identify the sealing threshold of the contact and that threshold is shown in Figure 19. The sealing limit is also shown as a dotted red line in Figure 14.

\section{Discussion}

The fluoroelastomer compound used for the stern tube seal studied was tested under various strains and loading conditions. A strong Mullins effect was observed, so the maximum strain ever reached by the elastomer determines its stress response. The relative stress relaxation was shown to be dependent on the strain, i.e. it exhibited non-linear viscoelastic behavior. A strong viscoelastic component was identified at ambient temperature which, as expected, reduces as the distance between the current and glass transition temperature $T_{g}$ increases. Consequently, the temperature-dependent material behavior observed at $20^{\circ} \mathrm{C}$ vanished at $40^{\circ} \mathrm{C}$ leading to a temperature-independent rubbery plateau. Note that under dynamic loading conditions, the damping due to the viscoelasticity of the material would be completely different at $20^{\circ} \mathrm{C}$ to what it would be at $40^{\circ} \mathrm{C}$, affecting the followability of the seal. The maximum strain level that a particular seal reaches is not easily determined. The radial load measurements of brand-new seals are slightly higher than those for seals which had been previously stretched (to larger strains) and then tested. In addition, to avoid disassembling the whole propeller, stern tube seals are cut, stretched around the shaft, and later re-joined, thereby achieving this way an even higher maximum strain. Therefore, the specific seal assembling procedure partially determines the resultant seal-shaft contact force when mounted.

The constitutive hyperelastic Yeoh model was chosen for its simplicity and was calibrated against the stress values obtained once the greatest part of the stress-relaxation decay had occurred. By using a hyperelastic constitutive material model, the seal is treated as perfectly elastic, so there is no provision for permanent strain deformation (zero stress leads to zero strain). Hyperelastic models disregard the maximum strain dependence and assume that the material response is the same under loading and unloading situations. However, such simplifications will inevitably add to the inaccuracy of the model.

The contribution of the Garter spring to the total seal-shaft contact force was obtained by measuring the spring characteristic and estimating its radial force once assembled and mounted on the shaft.
The spring load estimation obtained by applying equation (8) was in agreement with the measurements carried out on the split-shaft setup.

The validation of the static FE model presented several challenges. A large-dimension split-shaft test bench was built, so the radial force could be measured. The method presented consists of measuring the radial load for four different configurations. Such approach first allowed the validation of the constitutive material model, then the Garter spring contribution, and finally, the seal-housing clamping boundary conditions. However, the ability to predict the correct radial force under ambient conditions does not guarantee that the model is representative of the seal. An alternative validation method is presented which involves mounting the seal on a hollow glass shaft, so the contact width between seal and liner can be measured. However, under ambient conditions, the contact width of most seals is of the order of a few hundred micrometers, hampering accurate measurement. Furthermore, at such a scale, the roughness of the seal or marginal misalignments influences the measurement. For that reason, a specialized setup consisting of a transparent shaft and two sealing chambers was built. That setup allowed testing under actual application conditions under which larger stresses and strains develop due to the imposed external pressure. The position and the width of the contact at a range of operating pressures could be readily measured and showed good agreement with the predictions of the FE model.

A third novel method was introduced to further validate the two-scale model developed. The percolation threshold of the stern tube seal, i.e. the pressure difference required for the seal to leak, was measured by pressuring the seal on the glass shaft setup. Hereby, this time, a higher pressure was imposed in the backside than in the spring-side (inverse pressurization).

Using the perfectly smooth macroscopic FE model, the decrease in contact pressure resulting from inversely pressurizing the seal was predicted and is shown in Figure 14 in blue. Notice that, due to roughness, leakage occurs before the -0.4 bar pressure difference that is required to completely lift the seal. The estimated contact pressure was found to be in good agreement with that required for the microscale $\mathrm{BE}$ contact model to achieve an effective sealing barrier (shown by a red-dashed line in Figure 14). The shaded area corresponds to the pressure differences that lead to a contact pressure that is inferior to that required for a tight contact, i.e. the pressure differences causing leakage.

A variation of $\pm 10 \mathrm{~N}$ in the radial force measurements was observed when measuring seals even from the same batch. As well as the inherent model simplifications, the seal dimensional accuracy, elastomer curing state, or the strain history of the seal can explain this difference. The dimensional accuracy of the components of both the split-shaft and glass 
setups will also influence the results. Furthermore, the assembly of the stern tube seal to the housing components does not guarantee an accurate centering. It was decided to present frictionless results since stern tube seals most frequently operate under fully flooded conditions (near the transition of mixed to full-film lubrication).

Extrapolation of the results presented for the dynamic operation of a stern tube seal must be carried out with care. Even if boundary lubrication conditions are assumed, i.e. the shaft-seal load is fully supported by the shaft and seal asperities, neither the seal-tip displacement in the circumferential direction nor the friction heating of the seal tip has been included in this study. These could otherwise influence the results.

\section{Conclusions}

A multi-scale model of a stern tube seal has been developed. The model couples the macro and microscales, allowing the prediction of strains, stresses, temperature distribution, and percolation threshold under a wide range of pressures and temperatures.

Special attention was paid to the validation of the model. Two specialized setups were developed, so that the model was validated under pressurized conditions via radial force, contact width, and leakage rates, and showed a high degree of accuracy. Following the steps presented, the seal constitutive material model, the Garter spring, and the implementation of the seal housing can be independently addressed. This approach increases the reliability of the overall model while granting its full understanding when improving its design. The strategy presented for modeling the contact on a lip seal constitutes a solid milestone toward developing more advanced, accurate, and reliable models of sealing components.

\section{Acknowledgements}

Andries van Swaaij, Eric de Vries, Henk-Jan Moed, Walter Lette, Hans van Hoek, and Jonne Postmes for their technical advice. Rob Dierink, Roy Kooijman, Bart Rooijmans, and Sebastian Schipper for their assistance with the development of the testing setups. François Perseil-Rouillard, Gijs Boerrigter, and Mauryn de Graaf for their contribution to the two-scale model.

\section{Declaration of Conflicting Interests}

The author(s) declared no potential conflicts of interest with respect to the research, authorship, and/or publication of this article.

\section{Funding}

The author(s) received no financial support for the research, authorship, and/or publication of this article.

\section{ORCID iD}

F Xavier Borras (D) https://orcid.org/0000-0002-9801-8780

\section{References}

1. Flitney R. Rotary seals. In: Seals and sealing handbook. Waltham: Butterworth-Heinemann, pp.105-288.

2. Drobny JG. In: Fluoroelastomers handbook: the definitive user's guide. Amsterdam, the Netherlands: William Andrew Publishing, 2016, pp.17-40.

3. Wennehorst B. On lubrication and friction in soft rough conformal sliding contacts. Hanover, Germany: Leibniz Universität Hannover, 2016.

4. Jagger ET. Rotary shaft seals: the sealing mechanism of synthetic rubber seals running at atmospheric pressure. Proc IMechE Part J: J Engineering Tribology 1957; 171: 597-616.

5. Horve LA. Shaft seals for dynamic applications. New York: Marcel Dekker Inc., 1996.

6. van Bavel PGM. The leakage-free operation of radial lip seals. Ph.D. Dissertation, Eindhoven University, The Netherlands, 1997.

7. Salant RF. Theory of lubrication of elastomeric rotary shaft seals. Proc IMechE Part $J$ : $J$ Engineering Tribology 1999; 213: 189-201.

8. Stakenborg MJL. On the sealing mechanism of radial lip seals. Tribol Int 1988; 21: 335-340.

9. Marek G. On friction reduction in rubber lip seals for rotating shafts. Seal Technol 1997; 40: 8-11.

10. Sinzara W, Sherrington I, Smith EH, et al. Effects of eccentric loading on lip seal performance. In: 6th European conference on lubrication management and technology (Lubmat 2018), San Sebastian, Spain, 2018.

11. Frölich D, Magyar B and Sauer B. A comprehensive model of wear, friction and contact temperature in radial shaft seals. Wear 2014; 311: 71-80.

12. Engelke T. Einfluss der elastomer-schmierstoff-kombination auf das betriebsverhalten von radialwellendichtringen (in German). Hanover, Germany: Leibniz Universität Hannover, 2011.

13. Lee CY, Lin CS, Jian RQ, et al. Simulation and experimentation on the contact width and pressure distribution of lip seals. Tribol Int 2006; 39: 915-920.

14. Tasora A, Prati E and Marin T. A method for the characterization of static elastomeric lip seal deformation. Tribol Int 2013; 60: 119-126.

15. Pinedo B, Aguirrebeitia J, Conte M, et al. Tri-dimensional eccentricity model of a rod lip seal. Tribol Int 2014; 78: 68-74.

16. El Gadari M, Fatu A and Hajjam M. Shaft roughness effect on elasto-hydrodynamic lubrication of rotary lip seals: experimentation and numerical simulation. Tribol Int 2015; 88: 218-227.

17. Chung KK and Woo JS. Analysis of contact force and thermal behaviour of lip seals. Tribol Int 1997; 30: 113-119.

18. Wenk JF, Stephens LS, Lattime SB, et al. A multi-scale finite element contact model using measured surface roughness for a radial lip seal. Tribol Int 2016; 97 : 288-301.

19. Gabelli A, Ponson F and Poll G. Computation and measurement of the sealing contact stress and its role 
in rotary lip seal design. In: 13th International Conference on Fluid Sealing. BHRA, Brugge, Belgium, April 1992.

20. Borras FX, de Rooij MB and Schipper DJ. Rheological and wetting properties of environmentally acceptable lubricants (EALs) for application in stern tube seals. Lubricants 2018; 6: 100.

21. Bergström J. Elasticity/hyperelasticity. In: Mechanics of solid polymers (ed W Andrew). Amsterdam, the Netherlands: Elsevier, pp.209-307.

22. Rodas CO, Zaïri F, Naït-Abdelaziz M, et al. Temperature and filler effects on the relaxed response of filled rubbers: experimental observations on a carbon-filled SBR and constitutive modeling. Int $J$ Solid Struct 2015; 58: 309-321.

23. Vandenbroucke A, Laurent $\mathrm{H}$, Aït Hocine $\mathrm{N}$, et al. A hyperelasto-visco-hysteresis model for an elastomeric behaviour: experimental and numerical investigations. Comput Mater Sci 2010; 48: 495-503.

24. Dalrymple T, Choi J and Miller K. Elastomer ratedependence: a testing and material modeling methodology. In: 172nd technical meeting of the rubber division of the American Chemical Society, Inc. Cleveland, $\mathrm{OH}$, USA, 2007.

25. Shahzad M, Kamran A, Siddiqui MZ, et al. Mechanical characterization and FE modelling of a hyperelastic material. Mater Res 2015; 18: 918-924.

26. Bazrafshan M, de Rooij MB, Valefi M, et al. Numerical method for the adhesive normal contact analysis based on a Dugdale approximation. Tribol Int 2017; 112: $117-128$.

27. Hidrovo CH and Hart DP. Development of a dual purpose visualization technique for the study of rotating shaft seals. In: 3rd ASME/JSME joint fluids engineering conference, San Francisco, USA, 1999, pp.1-6. New York, NY: ASME.

28. Gabelli A and Poll G. Formation of lubricant film in rotary sealing contacts: part I: lubricant film modeling. J Tribol 1992; 114: 280.

29. Chapter 8: Garter springs. In: Design handbook: engineering guide to spring design. Bristol, CT: Barnes Group, pp.56-59.

\section{Appendix}

\section{Notation}

$\mathbf{b}^{*}$

distortional part of left Cauchy-Green tensor $(-)$

$C_{p} \quad$ specific heat capacity $(\mathrm{J} /(\mathrm{kg} \cdot \mathrm{K}))$

$C_{i 0} \quad$ Yeoh hyper-elastic model parameters (MPa)

$D_{r i} \quad$ inner diameter of the Garter spring before assembled ( $\mathrm{mm})$

$D_{s} \quad$ shaft diameter $(\mathrm{mm})$
$E$

$E^{\prime}$

$E^{\prime \prime}$

$E^{*}$

$F_{m}$

$F_{r}$

$I_{1}^{*}$

J

$k$

$K_{s}$

$L_{c}$

$\epsilon$

$p$

$P_{c}$

$P_{I}$

$P_{r}$

$r, z, \phi$

$S$

$S_{a}$

$S_{k}$

$S_{p}$

$S_{q}$

$S_{v}$

$S_{z_{5}}$

$T_{g}$

$u_{e}$

$x, y, x^{\prime}, y^{\prime}$

$\alpha_{\mathrm{T}}$

$\beta$

$\alpha$

$\delta$

$\kappa$

$\lambda_{i}$

$\mu_{s}$

$v$

$\rho$

$\sigma$

$\psi$

$\omega$
Young modulus (MPa)

storage modulus (MPa)

loss modulus (MPa)

complex elasticity modulus ( $\mathrm{MPa})$

load exerted by the stepper motor $(\mathrm{N})$ radial inwards force per unit length

$F_{r}=F_{r_{t o t}} /\left(\pi D_{s}\right)(\mathrm{N} / \mathrm{mm})$

distortional part of the first invariant of the right Cauchy-Green tensor $(-)$ Jacobian: determinant of the deformation gradient (-)

thermal conductivity $(\mathrm{W} /(\mathrm{m} \cdot \mathrm{K}))$

kurtosis of the surface roughness $(-)$ contact width (axial direction) $(\mathrm{mm})$ engineering strain $\epsilon=\left(L-L_{0}\right) / L_{0}(p-)$ contact pressure from Boussinesq solution $(\mathrm{MPa})$

spring circumferential load $(\mathrm{N})$

pretension of the spring $(\mathrm{N})$

spring radial load $(\mathrm{N} / \mathrm{mm})$

radial, axial, and circumferential cylindrical coordinates $(\mathrm{mm}, \mathrm{mm}$, rad)

spring stiffness $(\mathrm{N} / \mathrm{mm})$

average surface roughness $(\mu \mathrm{m})$

skewness of the surface roughness $(-)$ height of the tallest surface roughness peak $(\mu \mathrm{m})$

root mean square (RMS) of the surface roughness $(\mu \mathrm{m})$

height of the deepest surface roughness valley $(\mu \mathrm{m})$

average maximum surface height difference $(\mu \mathrm{m})$

glass transition temperature $(\mathrm{K})$

elastic deformation from Boussinesq

solution $(\mu \mathrm{m})$

coordinates of the surface in BE model (mm)

thermal expansion coefficient $(1 / \mathrm{K})$

spring-side lip seal angle (scraper angle) ( )

back-side lip seal angle (barrel angle) $\left(^{\circ}\right)$ phase lag between stress and strain $\left(^{\circ}\right)$ bulk modulus of the seal material (MPa) principal stretches $\lambda=1+\epsilon(-)$ coefficient of static friction between seal and liner (-) Poisson ratio (-) density $\left(\mathrm{kg} / \mathrm{m}^{3}\right)$

Cauchy stress (nominal stress) (MPa) elastic strain energy density $\left((\mathrm{N} \cdot \mathrm{m}) / \mathrm{m}^{3}\right)$ shaft angular velocity ( $\mathrm{rad} / \mathrm{s})$ 